\title{
Investigation of Cryogenic Technique for Synthetic Natural Gas Upgrading
}

\author{
CANSU BIRGEN, SILVIA GARCIA \\ Elvevegen 28, Trondheim/NORWAY \\ cansubirgen@gmail.com
}

\begin{abstract}
Biomass-based liquefied natural gas (bio-LNG) which is produced by liquefying synthetic natural gas (bio-SNG) is a valuable renewable fuel as it has high energy density and transportability. Cryogenic technology is a promising option for integration of the gas upgrading and liquefaction systems with the main biomass gasification and methane synthesis plant. This study investigates the feasibility of this technology for future commercial bio-SNG production plants based on indirect gasification technology, similar to that adopted by Göteborg Energi for the GoBiGas project. Simulation program Aspen Plus and pinch analysis tool Pro_Pi are used to compare conventional gas cleaning and liquefaction technology and cryogenic technology. The cryogenic unit achieves the targeted product specifications and capacity, and the calculated performance is comparable to published data for commercial units. The results show that the integrated plant with cryogenic technology has a higher power requirement than the plant with conventional technology. Cryogenic technology is still under development, therefore there is a high potential for performance improvement by application of energy efficiency measures. In addition, high purity liquid CO2 is produced at very low temperature as a by-product which could generate additional revenue.
\end{abstract}

Keywords: Cryogenic, bio-SNG, bio-LNG, gas upgrading, liquefaction 


\section{INTRODUCTION}

There is an ecological overshoot in which society is using more resources than nature can regenerate causing environmental and economic consequences. These problems have resulted in new policies that have stimulated research leading to variety of solutions ranging from technical improvements to new process routes for energy conversion processes.

The conversion of energy from renewable sources plays a major role for energy supply security as well as to reach climate and energy targets that were established by the European Commission's directive on the promotion of the use of energy from renewable sources (the "Renewable Energy Directive"). These mandatory targets are often referred to as the 20-2020 targets which are planned to be achieved by 2020 . EU energy consumption from renewable sources is set to reach $20 \%$ [1].

Renewable fuels as renewable energy source refer to fuels produced from renewable biomass or waste feedstock. They can be used for heat or electricity production and as a motor vehicle fuel as well. Bio-SNG (renewable substitute natural gas) has similar quality to fossil natural gas but it is produced from renewable sources.

Bio-SNG produced by biomass gasification can replace fossil natural gas; however, it has to be cleaned and upgraded before final use. Among other commercial upgrading techniques, cryogenic method has drawn attention recently. It makes use of the difference in condensation points of the gases in bio-SNG mix; the gases are separated from each other by consecutive cooling, condensation and separation units. It is an interesting option for both gas upgrading and bio-LNG (renewable liquefied natural gas) production with the additional benefit of producing high-purity liquid $\mathrm{CO} 2$ as a by-product. Bio-LNG is a valuable product since it has higher energy density compared to bio-SNG. Thus, it is easier to transport which is highly favorable especially in the case of use as a vehicle fuel.

\section{METHODOLOGY}

A literature study was conducted in order to gather data required to establish a simulation model of a bio-LNG production process. Material and energy balances are solved in the commercial flowsheeting software Aspen Plus from Aspen Technology. Process integration tool pro_PI is used to conduct pinch analysis with simulation results for both cases so that theoretical maximum work outputs are investigated.

In this study two different cases are defined to investigate cryogenic technique for gas upgrading; base case and integrated case. In base case, bio-LNG is produced in a liquefaction plant located immediately downstream of the main bio-SNG process. In integrated case a cryogenic unit is implemented directly within the process instead of conventional gas upgrading technology. Both processes are based on capacity assumption of $100 \mathrm{MW}$ of bioLNG and are inspired by GoBiGas design with addition of gas liquefaction unit [2]. Schematic representations of base case and integrated case can be seen in Fig. 1 and 2, respectively. 


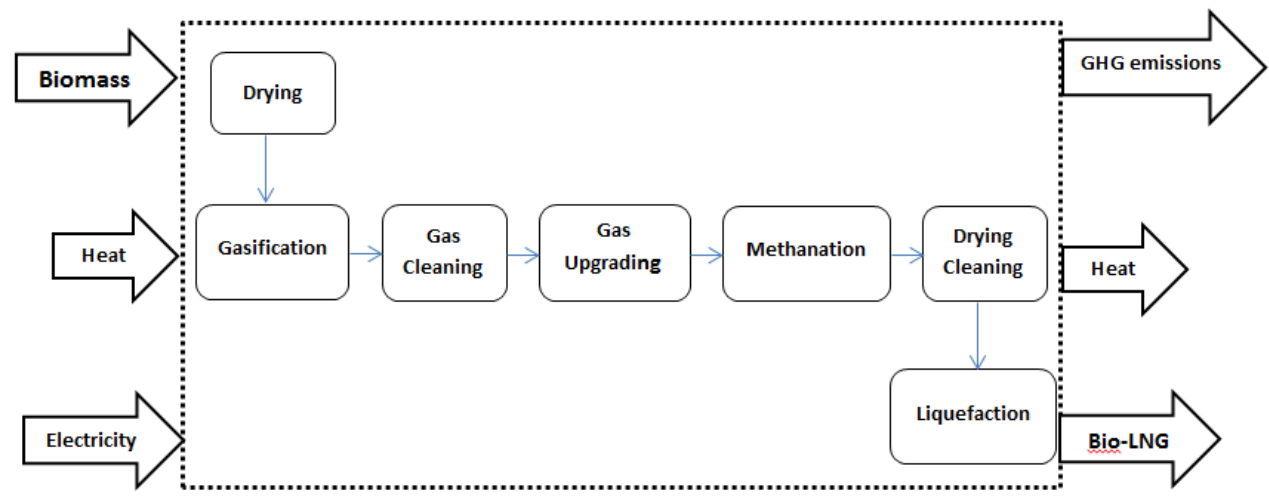

Fig. 1 Schematic representation of base case bio-LNG production process

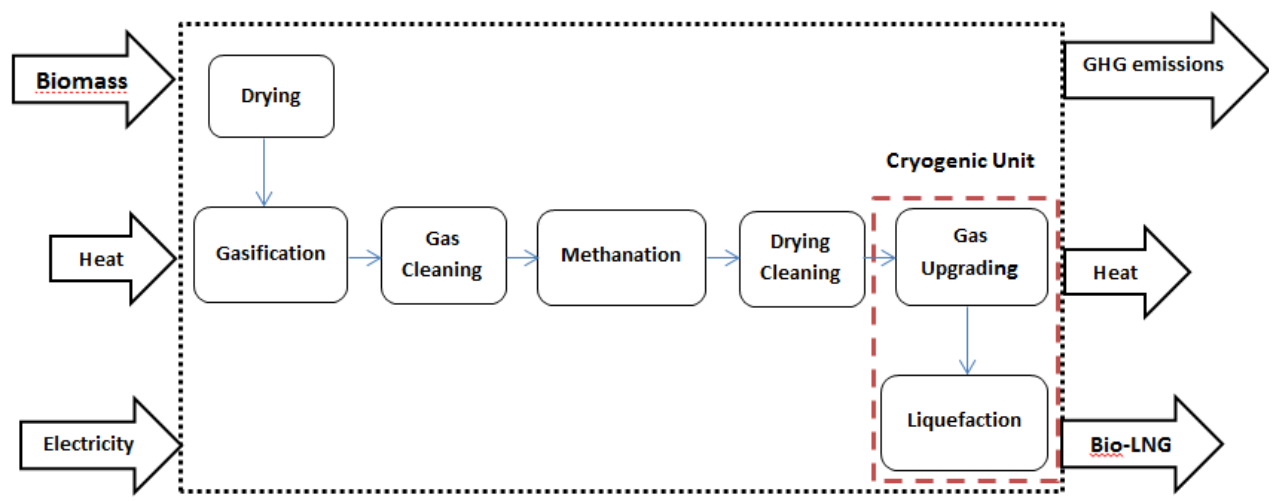

Fig. 2 Schematic representation of integrated case bio-LNG production process

The major difference in the designs is upgrading unit. In base case, it is kept as the same as in GoBiGas project which is chemical absorption technique applied before methanation while in integrated case cryogenic method is applied after drying and cleaning.

\subsection{Process Modelling}

Aspen Plus provides a rich property database, equations of state for different conditions and different models for common unit operations.

Biomass inlet consists of wet wood and it is modelled as a non-conventional solid [3]. Raw bio-SNG is produced after gasification and gas cleaning and it mainly consists of carbon dioxide, CH4 and trace amounts of hydrogen, carbon monoxide and water. Other existing components during the process that are removed are char, hydrocarbons, tars, sulphur compounds and trace compounds such as N2 and HCI. Final product is bio-LNG that is primarily $\mathrm{CH} 4$ in liquid state.

In this study, cryogenic unit for gas upgrading and liquefaction processes are simulated. The rest of the process simulation is based on Arvidsson et.al [4]. Liquefaction process modelling is considered for base case whereas cryogenic technique modelling together with liquefaction is considered for integrated case.

Process specifications and assumptions

Bio-SNG production is based on an existing design inspired by GoBiGas project.

Production capacity: 100 MWbio-LNG

Final delivery conditions: 7,5 bar and $-1630 \mathrm{C}$ 


\subsubsection{Base case}

Employed technology for bio-SNG liquefaction is based on a reverse nitrogen Brayton cycle. Pressure is a key variable in liquefaction process. In order to study the advantages and disadvantages of liquefying at high pressure, two designs that operate at different pressures are modelled in Aspen: high pressure case at 40 bar and low pressure case at 8 bar that is in the range of the delivery pressure in GoBiGas plant (5-10 bar).

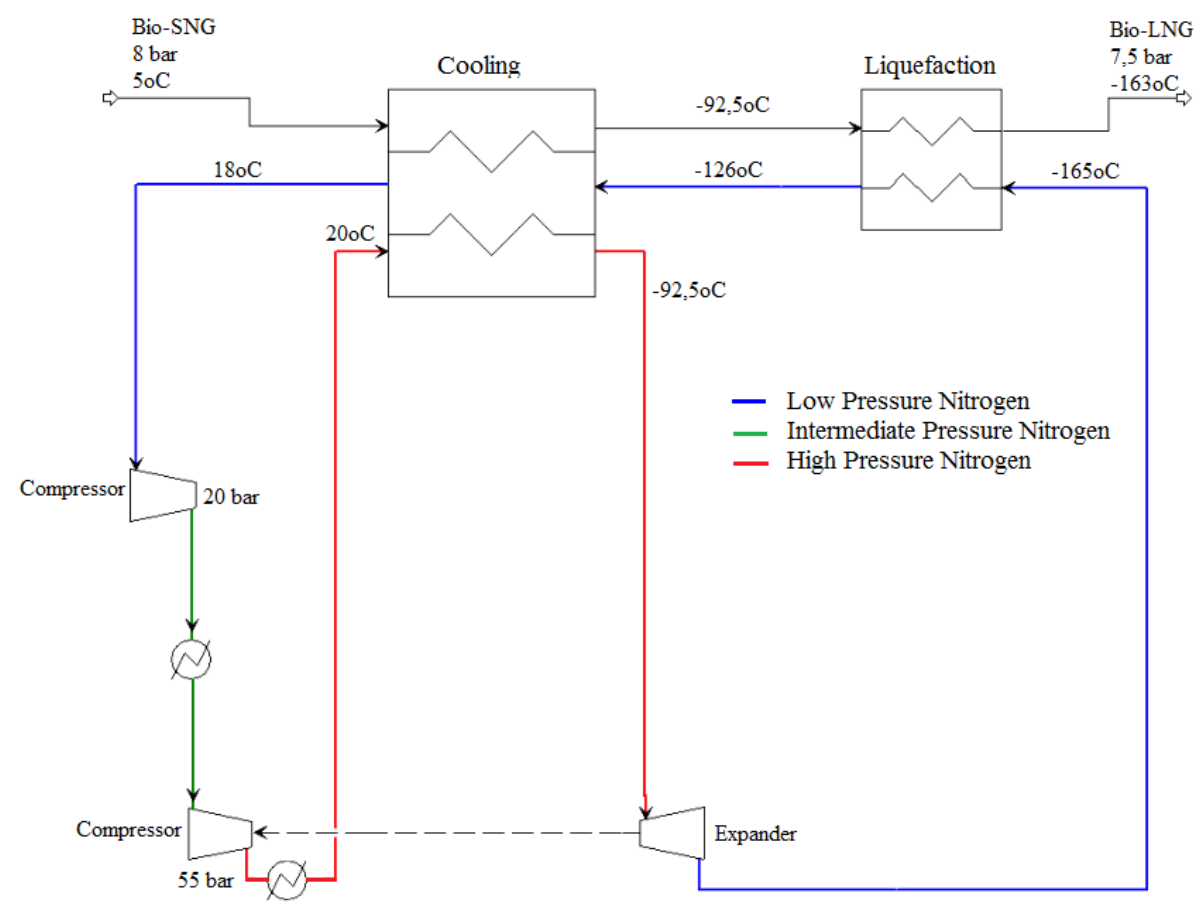

Fig. 3. Schematic illustration of cryogenic gas liquefaction by nitrogen expander at 8 bar

Bio-SNG coming from drying and gas cleaning and entering the liquefaction process is at 8 bar, therefore liquefaction occurs at $-130 \mathrm{oC}$ (Fig. 3).

First, low pressure N2 cools down the bio-SNG and the high pressure N2 to -92.5oC in order to achieve the desired specifications. In the second cooler, liquefaction of bio-SNG occurs. Coolers decrease refrigerant temperature to ambient temperature and the pressure in the compressors is in the ranges determined in process specifications. 


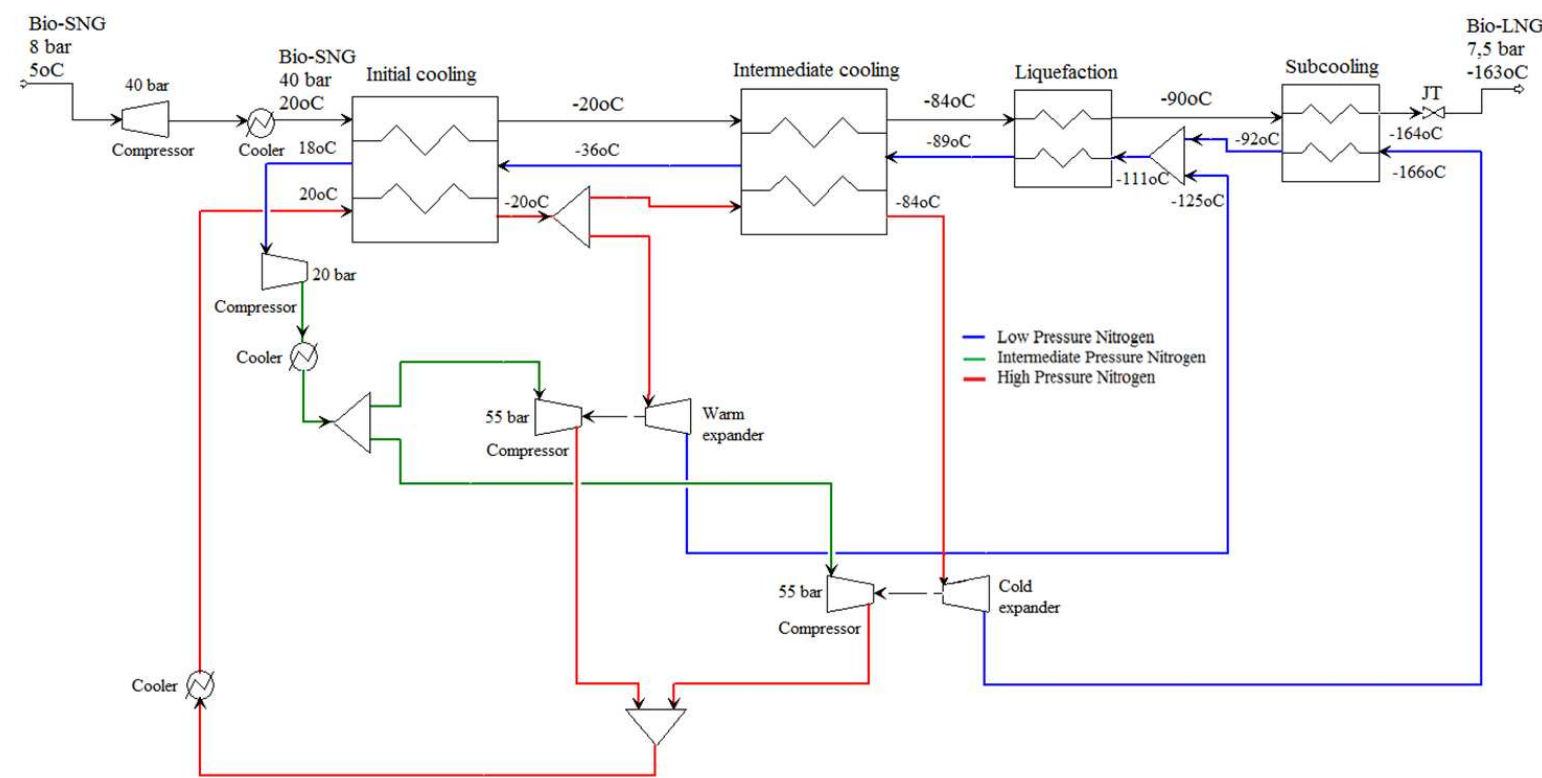

Fig. 4. Schematic illustration of cryogenic gas liquefaction by nitrogen expander at 40 bar

Liquefaction occurs at $-880 \mathrm{C}$ (Fig. 4). Hence, it is not required to expand all refrigerant to the lowest temperature as the lowest temperatures are only required for bio-LNG sub-cooling.

Operating conditions for all coolers and compressors are kept as in liquefaction at 8 bar. Split fraction is chosen to avoid excess work done by the process. It divides high pressure nitrogen stream into two different streams: the amount required for sub-cooling and the rest which is mixed before liquefaction with the outlet low pressure nitrogen stream from subcooling [5].

\subsubsection{Integrated case}

Integrated case is designed to produce bio-LNG from raw bio-SNG by applying cryogenic technique. Aspen model of the cryogenic process can be seen in Fig. 5.

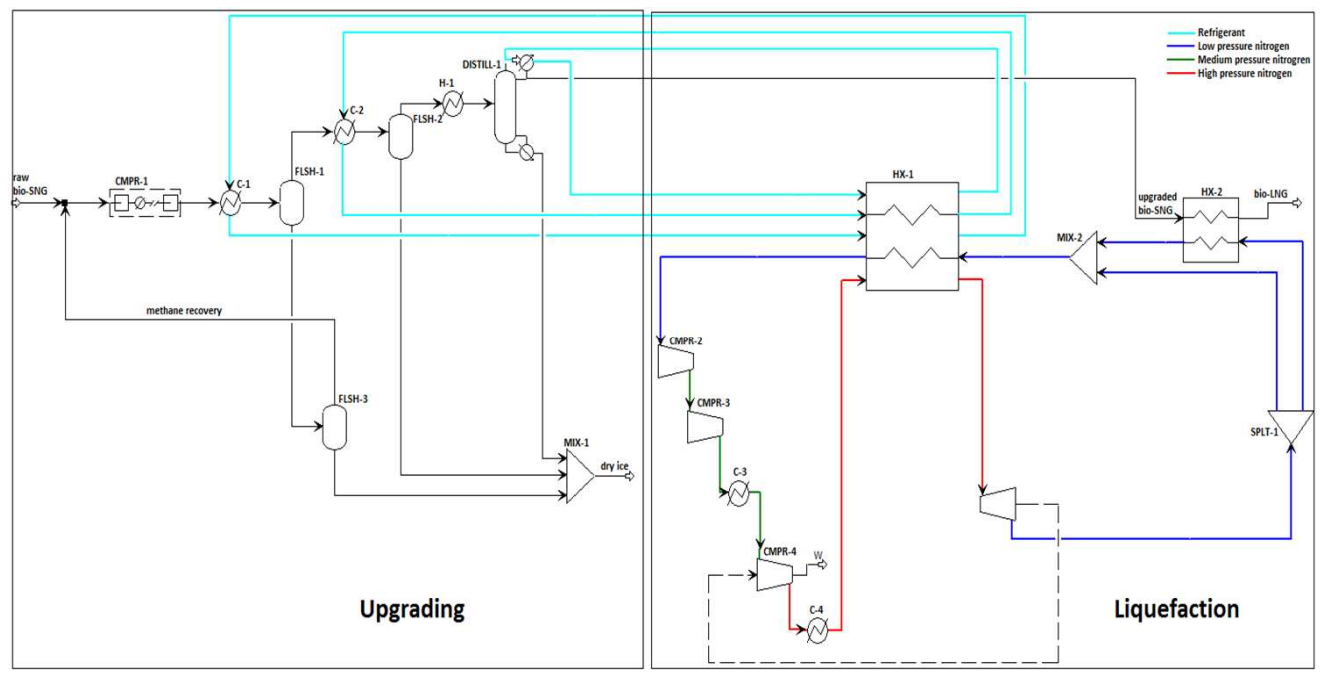

Fig. 5. Schematic illustration of cryogenic gas upgrading and liquefaction

Aspen model of the cryogenic upgrading unit is based on a model designed by Swedish Gas Center and the data was published in 1997 [6]. Raw gas is upgraded first to decrease CO2 content, and then liquefied. Nitrogen Brayton cycle liquefaction unit is designed to supply refrigerant to the upgrading unit and liquefy bio-SNG. 
First, raw gas is compressed to 65 bar. Compressed gas stream is cooled to $-51 \mathrm{oC}$ and flashed where first $\mathrm{CO} 2$ separation is achieved. Bottom stream of the flash tank is flashed further in for $\mathrm{CH} 4$ recovery, and recovered $\mathrm{CH} 4$ is mixed with inlet raw bio-SNG stream. Top stream of the flash tank is cooled to $-56 \mathrm{oC}$ and sent to another flash where more $\mathrm{CO} 2$ is separated. Product stream with high CH4 content is heated to sublimate solid CO2 content of it and fed to a distillation column to meet inlet purity requirement of the liquefaction unit. Upgraded bioSNG enters the liquefaction process at 7.65 bar, and $-1290 \mathrm{C}$. Final product, bio-LNG, is in the same conditions as in base case which are 7.5 bar and $-1630 \mathrm{C}$ as stated before in process specifications.

\subsection{Process Integration}

Process integration is a tool used in process design that analyse the energy use of a system as a whole. Instead of optimising process units separately, interaction between different unit operations is considered in order to minimise resource use [7]. In this study, heat integration within the process is investigated using Pinch technology.

Pinch technology refers to the combination of pinch analysis and process design based on pinch rules. It is used for determination of the minimum heating and cooling demand of a process, and to identify potential process energy efficiency improvements [3].

For the pinch analysis, an Excel add-in called pro_PI is used. First step is mapping the process streams. Inlet and outlet temperatures as well as heat heating and cooling demands for each stream are identified. Exergy concept using Carnot efficiency based curves is applied in combination with Pinch Analysis which enables targeting for shaft power savings in low temperature processes [8]. Exergy is defined as the theoretical useful work (shaft work or electrical work) obtainable as two systems interact to equilibrium or the minimum theoretical work required bringing matter to a specified state [9]. Based on a study of the integration of a steam cycle for combined heat and power (CHP) production to the SNG production process, values for exergetic efficiency close to 0.7 can be expected for cases with a high level of thermal integration [3].

\subsection{Process Evaluation}

After process simulation and pinch analysis, both cases are evaluated using some performance indicators that are explained below. In order to evaluate the energy consumption of both techniques, cold gas efficiency and overall energy efficiency are defined.

The cold gas efficiency $(\eta c g)$ is a measure that relates the heat produced in the final product depending on the energy input of the biomass inlet [3]:

$\eta_{c g}=\frac{\dot{m}_{\text {hin-INGs }} \cdot L H V_{\text {hin-I.NF }}}{\dot{m}_{\text {Wet wood }}-\text { LIIV wot wood }}$

where $\dot{m}$ is the mass flow and LHV the lower heating value

The overall energy efficiency $(\eta)$ can be defined as the useful heat transferred in relation to the energy supplied:

$\eta=\frac{\sum \dot{m}_{\text {products }} L H V_{\text {products }}+\sum W^{-}-\sum Q^{-}}{\Sigma \dot{m}_{\text {input }} \cdot L H V_{\text {input }}+\Sigma W^{+}+\Sigma \dot{Q}^{+}}$

where $\dot{Q}^{-}$and $\dot{Q}^{+}$represents useful heat departing or entering the system whereas $\dot{W}^{-}$and $\dot{W}^{+}$the mechanical power

In this study power production from excess heat is estimated and it is considered in overall energy efficiency. 


\section{RESULTS and DISCUSSION}

A main constraint in GoBiGas Project is the power requirement [2]. Thus, it is considered as a key factor in this study. For base cases, total power demand is the sum of power demand for upgraded bio-SNG production and its liquefaction. For integrated case, it is the sum of power demand for raw bio-SNG production, and the cryogenic technology (upgrading and liquefaction). Total power demands which are the sum of all power consuming devices e.g. pumps, compressors are directly taken from simulation results.

Exergetic efficiency of 0.7 is used for the estimation of the power production from the recoverable excess heat for the different cases investigated [3]. Results are obtained by assuming that all excess heat is recoverable for power production via a steam cycle. In fact, there are process restrictions e.g. limitations due to impurities in the hot streams or maintenance issues in power cycle; however, this method still gives a good estimation of the differences in power production potential of the processes as they have same characteristics.

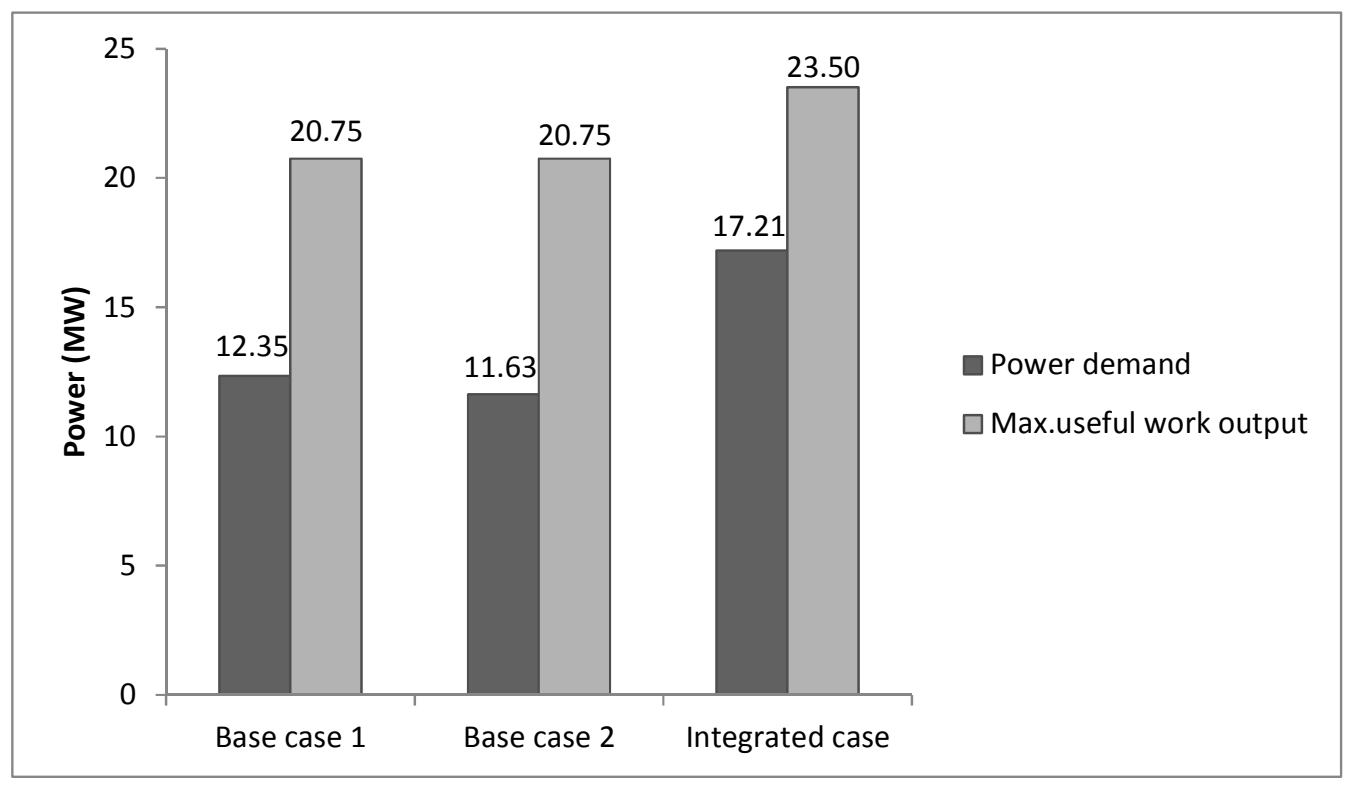

Fig. 6. Total power demands and power production potentials for three cases

Integrated case has higher power demand since cryogenic technology requires high pressures (65 bar) as separation is achieved by expansion in flash tanks. Furthermore, the refrigerant that is needed in the process is produced in the refrigeration cycle, which leads to more refrigerant mass flow, thus higher power demand in the compressors of the nitrogen cycle.

Difference between base case liquefaction power demands is because of the operating pressure. Base case 1 ( 8 bar) requires more refrigerant due to higher heat of evaporation. Liquefaction at 8 bar has higher duty, thus higher refrigerant mass flow. And, more refrigerant results in higher power consumption in compressors.

As can be seen in Fig. 6, all three cases have excess power which can be exported. Power production for integrated case is higher than base cases; however, its total power demand is the highest so that net power demand is the lowest. Base case 2 is the most feasible one as it has the maximum net power demand. 


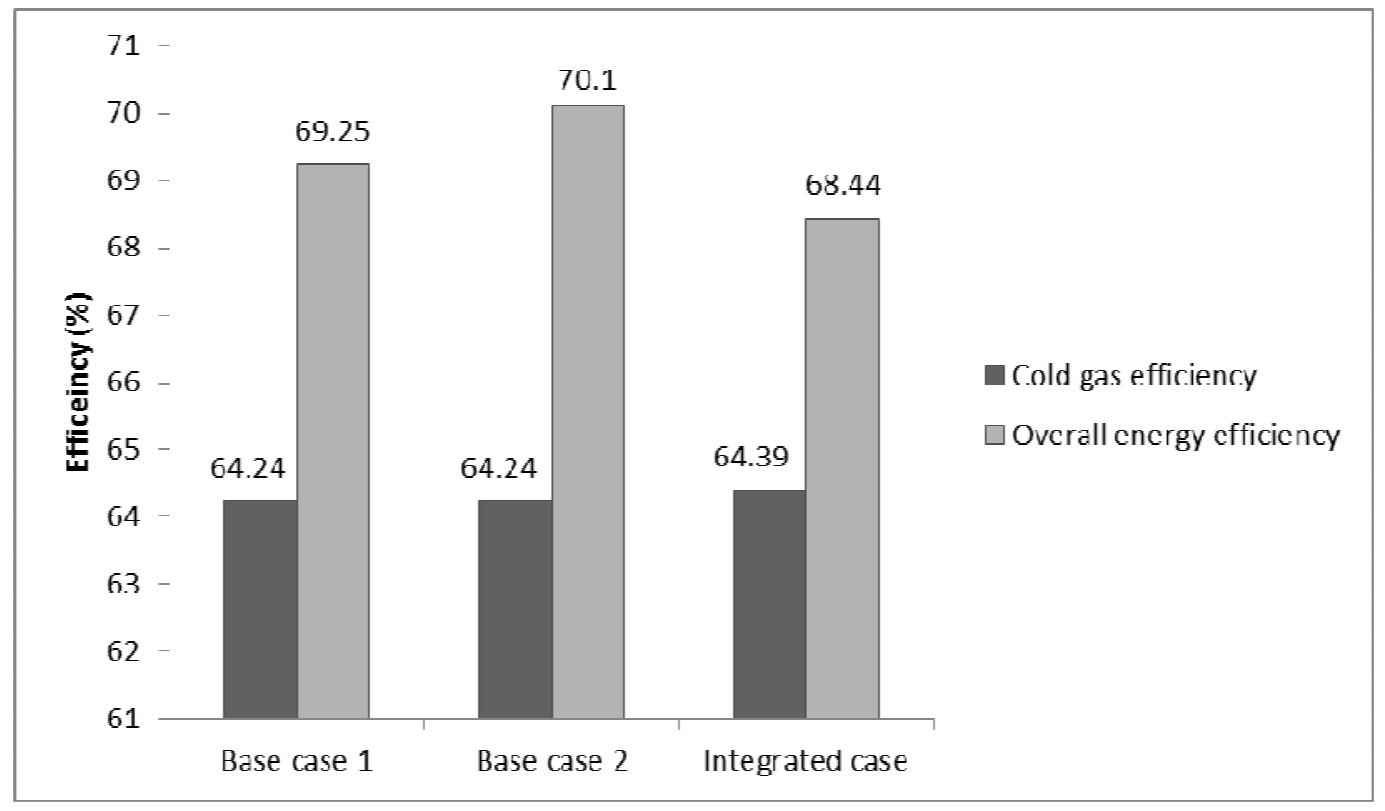

Fig. 7. Cold gas efficiencies and overall energy efficiencies for three cases

Cold gas efficiency of integrated case is slightly higher than base cases which is due to lower CH4 loss (Fig. 7). Therefore, less biomass is needed for same capacity (100 MW bio-LNG).

Energy content of the product and the feed (biomass) are almost the same for all cases. Moreover, useful heat entering/leaving the system is represented in terms of power in overall energy efficiency, since the excess heat is utilized for power production. Therefore, power demand and production are the key variables in calculating the overall efficiency values.

\section{CONCLUSION}

The analysis shows that the process with integrated cryogenic gas upgrading and liquefaction has slightly better cold gas efficiency in comparison with base case which employs a traditional upgrading gas upgrading and stand-alone liquefaction.

The calculated cold gas efficiency of integrated case is slightly higher than base cases, since there is lower $\mathrm{CH} 4$ loss in integrated case. The calculated overall energy efficiencies are $69.25 \%$ for base case $1,70.10 \%$ for base case 2 and $68.44 \%$ for integrated case. Integrated case is thus competitive in terms of energy performance with an added benefit of liquid $\mathrm{CO} 2$ production. In addition, cryogenic technology is not mature yet, thus there is a high potential for performance improvement by improved technology and enhanced process integration.

According to process simulation results, cryogenic upgrading technology results in very low $\mathrm{CH} 4$ losses which are connected to the flash separation. However, there is uncertainty due to simulation assumptions which might neglect other sources of CH4 loss. CH4 loss is loss of income but, in addition to that, it results in emissions of greenhouse gas, 20 times stronger than $\mathrm{CO} 2$ in case of $\mathrm{CH} 4$ leakage to the atmosphere from the system. However, they have small influence on the energy balance.

Very clean dry ice (or liquid CO2) is produced at very low temperature (-114oC) as byproduct that could be used in external processes. However, the disposal of this $\mathrm{CO} 2$ is very site specific, and it might require extra equipment e.g. dry ice has to be liquefied for collection and 
distribution as in the case of this study. Dry ice can be used within the process to take advantage of its exergy content since it is at low temperature, or it can directly be sold.

In places where the gas network is limited and the interest of using bio-LNG as a vehicle fuel is growing, it is a good alternative to fossil fuels. The production is energy intensive; however, it results in a more valuable product as it becomes available for a bigger market. The use of cryogenic technology also opens for more smart solutions where liquid $\mathrm{CO} 2$ and rejected heat could replace fossil fuel sources in external applications, affecting the energy balance in a positive way. Bio- LNG can also be used to fuel heavier vehicles, since it can be stored in its liquid state, therefore significantly increasing the driving range.

This study shows that cryogenic technique would be an interesting option for gas upgrading and liquefaction with an addition of cogeneration of power from the excess heat via a steam cycle to improve energy performance of the system.

\section{Acknowledgement}

This research paper is based on the master thesis project 'Liquefied Synthetic Natural Gas from Woody Biomass: Investigation of Cryogenic Technique for Gas Upgrading' held in Chalmers University of Technology in Department of Energy and Environment, Division of Heat and Power Technology. The project was held in collaboration with Göteborg Energi under supervision of Roman Hackl, Stefan Heyne and Ingemar Gunnarsson, and the examiner was Simon Harvey. We gratefully thank our supervisors, examiner and collaborators for their support and guidance.

\section{References}

[1] Council of the European Union, Presidency Conclusions, Retrieved 4th May, 2013 from http://www.consilium.europa.eu/

[2] Gunnarsson, I., The GoBiGas project - Efficient transfer of biomass to bio-SMG of high quality, SGC International Seminar on Gasification - Gas quality, CHP and new concepts, 2011, Malmö, Sweden

[3] Heyne, S., Bio-SNG from Thermal Gasification-Process Synthesis, Integration and Performance, Department of Energy and Environment, Chalmers University of Technology, 2013, Gothenburg, Sweden

[4] Arvidsson, M., Heyne, S., Morandin, M. and Harvey, S., Integration Opportunities for Substitute Natural Gas (SNG) Production in an Industrial Process Plant, Chemical Engineering transactions, 2012, Vol. 29

[5] Dubar, C, Liquefaction Process, US Patent, 1997, 5,768,912

[6] Swedish Gas Center, Adding Gas from Biomass to the Gas Grid, Report SGC 118, Retrieved 8th February, 2013 from http://www.sgc.se/ckfinder/userfiles/files/SGC118.pdf

[7] Smith, R., Chemical Process-Design and Integration. England: Wiley, 2005

[8] Hack R., Harvey S., Applying Exergy and Total Site Analysis for Targeting Refrigeration Shaft Power in Industrial Clusters, Energy, 2012

[9] Bejan A., Tsatsaronis G., Moran M., Thermal Design and Optimization, New York, NY; John Wiley \& Sons, 1995 